\title{
Relationship between Georgian-Persian biliterate additive bilingualism and learners' proficiency in English as a foreign language
}

Googoonani, Mohsen

English Department, Isfahan Branch, Islamic Azad University, Isfahan, Iran (mohsen_sandro@yahoo.com) Simin, Shahla $\triangle$

Farhangian University, Iran (shahlasimin@yahoo.com)

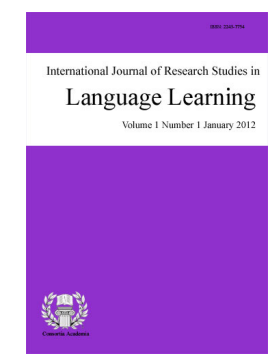

ISSN: $2243-7754$ Online ISSN: 2243-7762

OPEN ACCESS

\section{Abstract}

Third language acquisition (TLA) is a broad, complex, and also new topic of research. The present research aimed to find out the relationship between Georgian-Persian biliterate additive bilingualism on learners' proficiency in English as a foreign language. In this study, the participants were both monolingual and bilingual. Monolinguals live in Golpayegan, which is a monolingual region and people speak Persian. Bilinguals live in Ferydunshahr, which is a bilingual area, and Georgian and Persian are spoken there. All the participants were divided into two groups of $\mathrm{A}$ and $\mathrm{B}$. Each group consisted of 40 participants, both male and female, who were 14-18 years old. Monolinguals were studying English at the intermediate level in Arad Private Institute and bilinguals were studying English at the intermediate level in Pegah Omid Private Institute. After completing the questionnaires and tests by the participants, the results were analyzed. The findings indicated that there was no significant relationship between Georgian and Persian biliterary additive bilingualism and proficiency in English as a foreign language. The finding also showed that there was no significant relationship between languages typology and the third language acquisition. Based on the findings, it can be concluded that the income, education, and profession of parents had no effect on enhancing learners' language acquisition.

Keywords: language acquisition; monolingualism; bilingualism; multilingualism; biliteracy; additive bilingualism; language proficiency 


\section{Relationship between Georgian-Persian biliterate additive bilingualism and learners' proficiency in English as a foreign language}

\section{Introduction}

In each society, monolingual, bilingual or even multilingual people can be found who are living together. Monolingual people have the ability to use only one language. Bilingual people use two different languages, and multilingual people speak more than two. It is quite sensible take into consideration language acquisition as processes through which individuals acquire language. In general, acquisition of language points to children's native language acquisition, while the second language acquisition also looks into language acquisition as acquiring of another language in children and adults. Many of experts believe that language acquisition is one of the most important and compelling side of human development. Also, third language acquisition is a new area of research that has extended quickly during the recent years. A lot of studies have already done around the relationship between biliterate additive bilingualism and the acquisition of a third language (L3), but some contradictory results have been obtained. Of course, several research reported that bilinguals had some advantages over monolinguals. Obviously, because of some positive evidences against some negative or even neutral results, it will be impossible to generalize the results provided by studies on the effects of bilingual education on $\mathrm{L} 3$ acquisition.

In the current research, monolinguals live in a monolingual area where the people just speak Persian and bilinguals live in a bilingual area where Georgian and Persian are spoken. This is a noticeable point that all the monolinguals in the current study are living in the pure monolingual region and all the bilinguals are the active type. In a few cases of all previous researches have been done, the first language is completely different from the second and the third one and this is a key point. Here in this research, the majority of participants' first language is Georgian that belongs to Kartvelian family and is similar to Slavic languages. Georgian is different in language family rather than Persian and English. It is really important to consider typological distance or language distance as a potential phenomenon in the acquisition of foreign languages. Typology of the three languages is so important but this noticeable point has been neglected in many of previous research. To date, there is no definite evidence about the effect of language distance or typological distance on the process of L3 acquisition. Also, any special research does not have reported yet about the impact of a Slavic language on learning English. This research is a good attempt to fill this gap in language typology. Another key distinction that has been made in this study is that of bilingualism versus biliteracy.

Based on what has been discussed, this study is going to investigate appropriate answers to the following questions:

$>$ What is the relationship between Georgian and Persian biliterary additive bilingualism and learners' proficiency in English as a foreign language?

$>$ What is the role of languages typology in third language acquisition?

$>$ What is the relationship between parents' income and profession and learner's language acquisition?

$>$ Is there any significant relationship between learners' gender and their proficiency in English as a foreign language?

\section{Literature review}

There is a distinction between additive and subtractive bilingualism. If members of the majority group acquire an L2 in order to become bilingual and their first language still exists, bilingualism will results in 
additive linguistic consequences. If minority group members acquire an L2 which might replace their L1, bilingualism will result in subtractive linguistic consequences (Herdina \& Jessner, 2002).

Wagner, Spratt, and Ezzaki (1989) compared bilinguals literate in the L2 with monolinguals, while Cenoz and Valencia (1994) compared bilinguals literate in both the L1 and L2 with monolinguals. None of the studies separated bilingualism from biliteracy. In contrast, Swain, Lapkin, Rowen, and Hart (1990) isolated both variables by comparing biliterate bilinguals with bilinguals literate only in the L2. According to results, they concluded that the key to the cognitive advantage reflected in a more efficient L3 acquisition is biliteracy and not bilingualism. Bilinguals illiterate in their L1 did not perform significantly better than the monolingual group. In Sanz' (2000) study, as in Cenoz and Valencia (1994), all participants in the bilingual sample were biliterate, while all monolingual participants, unlike those in that study, and were true monolinguals that lived in a monolingual area. While, Cenoz and Valencia's monolingual participants lived in a bilingual area.

Another variable that investigated by Swain et al. (1990) is the typology of the three involved languages. They hypothesized that bilinguals whose L1 belonged to the Romance family would benefit the most from their bilingual experience and the positive influence it would exert in the acquisition of the L3 (French, likewise a Romance language). The evidence confirmed the hypothesis. In Sanz (2000) study, like Cenoz and Valencia (1994) and Wagner et al. (1989), language typology was not a variable under analysis. However, the four studies differed in the typology of the languages involved: Wagner et al.'s participants were native speakers of Berber learning Arabic as an L2 and French as an L3; Cenoz and Valencia's participants were native speakers of Basque or Spanish in a Basque bilingual program with English as their L3. In Sanz (2000) study, the participants were learning English as an L3, and both their L1 and L2 were Romance languages. In light of Swain et al.'s research, the relationship among the languages involved might also account for differences in the results of research on the effects of bilingualism on L3 acquisition.

Language distance might have some different interpretations. For instance, the Cenoz' (2001) study on bilinguals of Basque and Spanish targeting English equates informal similarity, since the linguists identify Spanish and English as closer languages because they belong to the Indo- European family and Basque is classified as more distance in relation to Spanish and English, since its origin is not Indo-European. Furthermore, Wagner, Spratt, and Ezzaki (1989) concluded that L1 (Berber) illiteracy does not hinder L2 (Arabic) or L3 (French) literacy, based on their own evidence from Morocco. In Wanger's (1989) research three different languages have been considered, while Cenoz and Valencia (1994), Swain et al. (1990), and Sanz (2000) considered all Indo-European languages and as Swain investigated as some other research, a key distinction made in this study is that of bilingualism versus biliteracy.

Study of literacy is one of the most recent factors as a distinct component of second and third language acquisition (Cenoz, 2013). Dewaele (2010) deduced that knowledge of other languages can facilitate TLA at intermediate levels of proficiency in the L3. Several studies have been carried out with immigrant bilingual learners in the Netherlands. For example, Sanders and Meijers (1995) reported no differences in the acquisition of English as a third language between immigrant Turkish-Dutch or Arabic Dutch bilingual learners and monolingual Dutch learners. Another study involving bilingual immigrant learners of an L3 was carried out in Brussels by Jaspaert and Lemmens (1990). Participants in this project were Italian immigrant children who were in a bilingual program in their L1 (Italian) and French and were learning Dutch as a third language. When the level of proficiency in Dutch of these Italian-French bilinguals was compared to that of French-speaking monolinguals, no significant differences were observed.

\section{Method}

\subsection{Participants}

In this study, all the participants are monolingual or bilingual. Monolinguals live in Golpayegan, which is a 
monolingual region and people speaking only Persian as their mother tongue. Bilinguals live in Ferydunshahr, which is a bilingual area, and Georgian and Persian are spoken there. Bilinguals exposed to these two languages from birth. Participants of the study are going to learn English as a foreign language. Bilinguals' first and second languages are Georgian and Persian. All the bilinguals are active type, who actively use their two languages in everyday life and are learning a third language. They are early bilinguals exposed to two languages from birth and now live in a bilingual context. They started to learn English as a subject at school at the age of 14 to 18 and do not have a lot of exposure to English. The participants, neither monolinguals nor bilinguals do not use English in their daily communication.

All the participants in the current study were divided into two groups. Group A consisted of monolinguals, who just speak Persian, and group B consisted of additive bilinguals, who speak both Georgian and Persian. Group A, as well as group B, consisted of 40 participants, goes halves on male and female, who are 14 to 18 years old and they are studying English at the intermediate level. Monolinguals are studying English in Arad private institute in Golpayegan and bilinguals are studying English in Pegah Omid private institute in Fereydunshahr. Participants from multilingual households (with languages other than Georgian and Persian) eliminated from the final sample.

\subsection{Instruments}

Background Questionnaire - The background questionnaire contained questions about learners' mother tongue, the age they started English, the number of years in an English speaking country, other languages they had studied, and the kind of instruction in English they have received at school.

Personal Information Sheet - Personal information sheet included age, gender, and so on. The questionnaire asks for approximate income and profession of both parents.

Oxford Quick Placement Test (OQPT) - In order to make sure that 80 literate EFL participants in groups A and B are at the same level of general English proficiency, the Oxford Quick Placement Test was administered. The Oxford Quick Placement Test is a valid and reliable test and it can also be used as a quick measurement of students' general language proficiency.

Intelligent Test - Intelligence was measured via Raven's Progressive Matrices Test. The Raven's Progressive Matrices (RPM) test paradigm is intended to measure educative ability, the ability to extract and process information from a novel situation (Raven \& Court, 2003).

Academic Language Exposure - Exposure to English included the number of English courses and the hours per course at school as well as in after-school programs and in summer programs. Participants' exposure to English was identified by asking question about the age they started to learn English and many of years they are studying English. These questions were available in background questionnaire. Also classroom activities, availability and use of instructional resources in the two target institutes were checked by a Likert-format questionnaire; adapted from Martínez, Bailey, Kerr, Huang, and Beauregard (2010). These two questionnaires completed by English teachers.

Motivation to learn English - "Motivation is a feeling of enthusiasm or interest that makes you determined to do something" (MacMillan English Dictionary, 2002, p. 975). The Motivation to learn English was measured by means of a Likert-scale questionnaire.

Attitudes - Attitudes toward the British and U.S. population and their other varieties of English were elicited by means of a questionnaire that followed Osgood's semantic differentials format. The attitude concept has three components: behavioral, cognitive and affective. These three attitudinal aspects are based on the three theoretical approaches of behaviorism, cognitivism and humanism respectively.

Final Exam - Four Corners Student's Book Level 2 and Level 3 are designed for high beginning young 
adult and low-intermediate students. Four corners series package provides standard quizzes and tests for students' midterm and final exam.

\subsection{Procedure}

The first phase was conducted as well as second phase, so the same strategy as used for bilinguals was used for monolinguals. The first phase deals with bilinguals in Fereydunshahr and the second phase was conducted with monolinguals in Golpayegan. Firstly, the OQPT was given to all participants in one administration. Then, based on their English proficiency, the purposive sampling selection was done. Then Raven's intelligent test was given to all monolinguals and bilinguals. Next, attitude and motivation questionnaires were administered. Their scores on OQPT, intelligent test, attitude and motivation questionnaires were obtained and submitted to SPSS for analysis. Based on their scores, monolingual and bilingual participants were selected and classified into separate groups. Next, all participants completed personal information form and background questionnaire. At the end, all the participants took part in the final exam. Classroom activities and configuration form and availability and use of instructional resources sheet were administrated by bilinguals' teachers. All tests and questionnaires were administered during the learners' regular class time. All the participants agreed to complete the tests and signed an ethics consent form. Besides, the learners in both groups were free to withdraw from the study at any time, and some did so.

\subsection{Statistical Analysis}

In order to answer the research questions in focus in this study, and to examine the relevant hypotheses, after collecting data, quantitative analysis was performed on the data. The scores were submitted to a descriptive analysis in SPSS. The collected data was analyzed by the SPSS aiming to answer the research questions quantitatively. The independent variables were language proficiency in English, attitudes toward the English as a foreign language and British and U.S. population, academic exposure to English, motivation to learn English, and finally the intelligence of language. The dependent variables were monolingualism and bilingualism.

\section{Results}

\subsection{Qualitative Section}

The following section, the qualitative findings are elucidated. For the qualitative part of the study, the researcher used some of the prevalent ways of eliciting data.

Results of Background Questionnaire - The background questionnaire contained eight questions. The results were presented in the tables. Moreover, if the quotations borrowed from the participants were in Persian, they were translated into English by the present researcher. The questions used in this interview and the results of the responses to each of questions are presented below:

Question 1: Where were you born?

According to the results, 38 participants were born in Fereydunshahr, 40 participants were born in Golpayegan, and just 2 participants were born in other cities.

Question 2: How old were you when you started to learn English?

Results showed that most of the participants started to learn English between their 12-15 years old.

Question 3: How many years have you been learning English (including the school)?

Based on the results, most of the participants had five years or more experience for studying English. 
Question 4: What is your mother tongue (i.e., the language you first acquired)?

As the results showed, all bilinguals' mother language was Georgian and all monolinguals' first language was Persian.

Question 5: How many languages do you speak?

According to the obtained results, all bilinguals can speak Georgian and Persian languages. However, all monolinguals just speak Persian.

Question 6: Do you have studied other languages? (If yes write the languages)

Based on the results, Participants did not have any experiences for studying other languages.

Question 7: At present, which language(s) do you use the most on a daily basis?

Obtained results say that all of the monolinguals use Persian for daily speaking. In bilinguals' group, 37 of them speak Georgian and just 3 people use Persian for daily dialogues.

Question 8: Which aspect of English did you study more?

As participants' answers in both group A and B, all of them study a mixture of vocabulary, grammar, and practice them in their English conversations.

Results of Personal Information Sheet - Personal information included participants' age, gender, course and level of the study, and also their both parents' approximate income, education, and profession. All the monolinguals and bilinguals go halves on male and female. Here 41 Participants were in Four Corners Level 3 Course, and 39 Participants were in Four Corners Level 4 Course. As shown in Figure 1, most of the fathers had Bachelor of Art and most of the mothers got their high school Diploma.

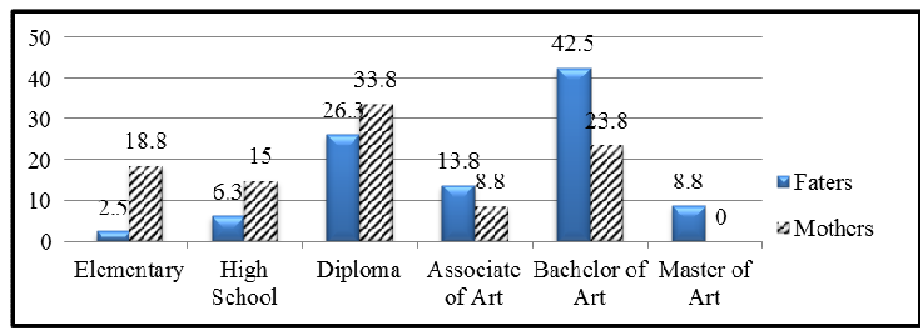

Figure 1. Fathers' and mothers' education

As the results are shown in Figure 2, most of the fathers were the employee or they had other professions and most of the mothers were the housewife.

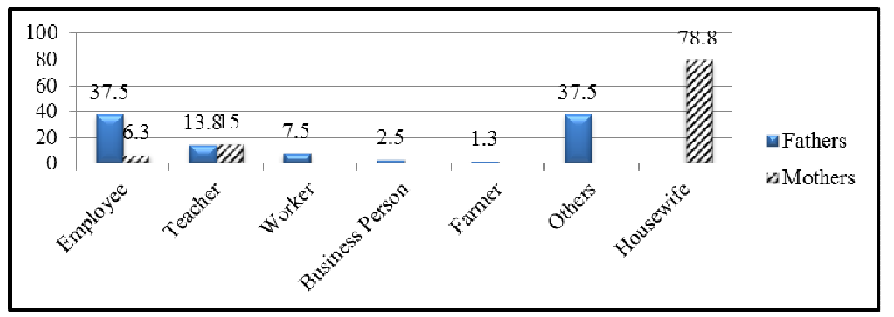

Figure 2. Fathers' and mothers' profession

In the last question of the personal information sheet, participants were asked about their parents' approximate income. Based on their answers, most of the parents had 1.5 million Tomans each month. Then as a same result, 26.3 percent of parents had 1 and 2 million Tomans. Only 17.5 percent of parents had more than 2 million Tomans per month. 


\subsection{Quantitative Section}

The data collected from the tests and questionnaires analyzed in relation to the purpose of the study using SPSS to conduct all the results.

Kolmogorov-Smirnov test (KS) - The two-sample KS test is one of the most useful and general nonparametric methods for comparing two samples.

Variables' Normality Test - In the current research, KS test was used to test for the normality of data, because there is more than one independent variable. Independent variables were socioeconomic status, language proficiency in English, attitudes toward the English as a foreign language and British and US population, academic exposure to English, motivation to learn English, and finally the intelligence of language. Monolingualism and bilingualism were dependent variables.

\section{Table 1}

KS test (For Independent Variables)

\begin{tabular}{lcc}
\hline \multicolumn{1}{c}{ Variable } & Z-Test of Normality & $p$ \\
\hline Attitudes towards English Language & 1.12 & .163 \\
Behavioral aspect & 1.25 & .086 \\
Cognitive Aspect & .06 & 1.34 \\
Emotional Aspect & .23 & 1.04 \\
Motivation & .06 & 1.30 \\
Intelligent Test & .156 & 1.12 \\
Oxford Quick Placement Test & .147 & 1.14 \\
Final Exam & .069 & 1.3 \\
\hline
\end{tabular}

Looking at Table 1 showed that all research variables were normal because P-Value was higher than .05 for all variables. So parametric statistical tests, like Independent T-test, One-Way ANOVA, and Scheffe's method tests were used for analyzing the research hypotheses.

Variables in Monolingual and Bilingual Groups - Firstly, participants' scores on OQPT, intelligent test, attitude and motivation questionnaires were obtained. In order to make sure that 80 literate EFL participants in groups A and B are at the same level of general English proficiency, their scores submitted to SPSS for analysis. The independent T-test was used because it is an inferential statistical test that determines whether there is a statistically significant difference between the means in two unrelated groups. Based on their scores, bilingual participants were selected and classified. Learners with very low or very high scores were omitted.

In statistics, Levene's test is an inferential statistic used to assess the equality of variances for a variable calculated for two or more groups. If the resulting p-value of Levene's test is less than the significance level (typically 0.05), the obtained differences in sample variances are unlikely to have occurred based on random sampling from a population with equal variances. Thus, the null hypothesis of equal variances is rejected and it is concluded that there is a difference between the variances in the population. According to the results, it was concluded that $\mathrm{p}$-Value for all variables, except intelligent test, was higher than 0.05; so variances for the variables are equal. p-Value for the intelligent test was less than 0.05 .

\subsection{Testing the Research Hypotheses}

Based on what was mentioned before, four research hypotheses were posed. This study sought to find any possible answers to them. The four hypotheses of the study were tested, the results of which would be yielded in details.

Research Hypothesis 1 - The first null hypothesis was expressed as follow:

$>\quad \mathrm{H}_{0} 1$.There is no significant relationship between Georgian and Persian biliterary additive bilingualism 
on learners' proficiency in English as a foreign language.

The analysis of this hypothesis involved several stages. T-test was set up to determine whether there is a statistically significant difference between the means in two unrelated groups. Levene's test was used to assess the equality of variances. If the p-Value from this test is less than 0.05 , then variances are significantly different. So a small p-value $(\leq 0.05)$ indicates strong evidence against the null hypothesis, and it is rejected. A large p-value ( $>0.05$ ) indicates weak evidence against the null hypothesis. So, data does not support a rejection of the null hypothesis and it will be true.

\section{Table 2}

English Proficiency Scores (Based on Monolingualism and Bilingualism)

\begin{tabular}{|c|c|c|c|c|c|c|c|}
\hline \multicolumn{3}{|c|}{$\begin{array}{c}\text { Independent T-test for Comparing } \\
\text { Means }\end{array}$} & \multicolumn{2}{|c|}{ Levene's Test } & \multirow{2}{*}{ Mean } & & \multirow{2}{*}{ Variable } \\
\hline $\mathrm{p}$-Value & $\begin{array}{l}\text { degrees of } \\
\text { freedom }\end{array}$ & $\mathrm{T}$ & $\mathrm{p}$-Value & $\mathrm{F}$ & & & \\
\hline .627 & 78 & .488 & .879 & .023 & $\begin{array}{l}91.65 \\
91.10\end{array}$ & $\begin{array}{l}\text { Group A } \\
\text { Group B }\end{array}$ & English Learning \\
\hline
\end{tabular}

As the results are shown in Table 2, the difference between means of two groups was not significant, and it was higher than 0.05. So, it was concluded that data were likely with a true null, and there is no significant relationship between Georgian and Persian biliterary additive bilingualism and proficiency in learning English as a foreign language.

Research Hypothesis 2 - As it was mentioned earlier, the second hypothesis of the current research was about languages typology. The following null hypothesis was proposed as follow:

$>\mathrm{H}_{0}$ 2. There is no significant relationship between languages typology and third language acquisition.

According to the results of independent sample T-test, and as results of the first hypothesis, languages typology has no effect on enhancing learners' proficiency in learning English as a foreign language. The difference between means of monolinguals' and bilinguals' groups was less than 0.05 , and it was not noticeable.

Research Hypothesis 3 - As mentioned before, the third hypothesis of the present study was about parents' approximate income, education, and profession. It was as follow:

$>\quad \mathrm{H}_{0} 3$. Income, education, and profession of both parents have no effect on enhancing learners' language acquisition.

Father and Mother's Education - The analysis of variance was used to deal with this hypothesis. According to the results in Table 3, the difference between means of research participants' answer, based on their father's education, was not significant, and it was higher than 0.05 . Therefore, it was concluded that data were likely with a true null, and father's education has no significant effect on learners' language acquisition.

As the means are shown in Table 4, students, whose fathers had M.A, had higher scores than other students. Nevertheless, the difference was not significant. Based on the third research question of the study, the main statistical procedures employed included Analysis of Variance. As can be seen at Table 5, there was not a significant difference among mother's education with respect to $\mathrm{F}=1.618$ at $p<.05$. Therefore, the third null hypothesis would be supported. As displayed in Table 4, students, whose mothers had Associate of Art, had the highest scores. Nevertheless, the difference was not significant. 
Table 3

Variance Test Based on Father's Education

\begin{tabular}{lccccc}
\hline & Sum of Squares & $d f$ & Mean Square & $F$ & Sig. \\
\hline Between Groups & 146.90 & 5 & 29.38 & 1.183 & .326 \\
Within Groups & 1837.85 & 74 & 24.84 & & \\
Total & 1984.75 & 79 & & & \\
\hline
\end{tabular}

Table 4

Means of English Proficiency Variable Based on Father and Mother's Education

\begin{tabular}{lcccc}
\hline \multirow{2}{*}{ Education } & Number of & Subset for alpha $=0.05$ & Number of & Subset for alpha $=0.05$ \\
\cline { 3 - 3 } \cline { 5 - 5 } & Fathers & 1 & 15 & 1 \\
\hline Elementary School & 2 & 92.50 & 12 & 91.13 \\
High School & 5 & 89.40 & 27 & 89.08 \\
Diploma & 21 & 90.81 & 7 & 91.37 \\
Associate of Art & 11 & 89.64 & 19 & 95.00 \\
Bachelor of Art & 34 & 91.82 & 0 & 91.68 \\
Master of Art & 7 & 94.71 & & .62 \\
Sig & & .64 &
\end{tabular}

Table 5

Variance Test Based on Mother's Education

\begin{tabular}{lccccc}
\hline & Sum of Squares & $d f$ & Mean Square & $F$ & Sig. \\
\hline Between Groups & 157.70 & 4 & 39.43 & 1.618 & .178 \\
Within Groups & 1827.05 & 75 & 24.36 & & \\
Total & 1984.75 & 79 & & & \\
\hline
\end{tabular}

Father and Mother's Profession - For this part of the third research hypothesis, a one-way analysis of variance (ANOVA) was adopted. As demonstrated by Table 6, no significant difference was observed among father's profession with respect to $\mathrm{F}=.637$ at $p<.05$. Therefore, it was concluded that data were likely with a true null.

Table 7 demonstrates mean score of father's profession, based participants' answers in the personal information sheet. This table indicates students, whose fathers were the teacher, had the highest scores. Despite this fact, the difference was not significant.

Table 6

Variance Test Based on Father's Profession

\begin{tabular}{lccccc}
\hline & Sum of Squares & $d f$ & Mean Square & $F$ & Sig. \\
\hline Between Groups & 81.86 & 5 & 16.37 & .637 & .672 \\
Within Groups & 1902.89 & 74 & 25.72 & & \\
Total & 1984.75 & 79 & & & \\
\hline
\end{tabular}

Eventually, the current research tried to figure out if there was any relationship between the mother's profession and learners' language acquisition. So, a one-way analysis of variance (ANOVA) was adopted. As can be seen at Table 8 , there was not statistically significant difference among mother's profession with respect to F. $=.252$ at $p<.05$. Thus, the third null hypothesis would be supported.

As shown in Table 7, scores for students, whose mothers were employee, were the highest. However, the difference was not significant. 
Googoonani, M., \& Simin, S.

Table 7

Means of English Proficiency Variable Based on Father and Mother's Profession

\begin{tabular}{|c|c|c|c|c|}
\hline \multirow{2}{*}{ Profession } & \multirow{2}{*}{$\begin{array}{l}\text { Number of } \\
\text { Fathers }\end{array}$} & Subset for alpha $=0.05$ & \multirow{2}{*}{$\begin{array}{c}\text { Number of } \\
\text { Mothers }\end{array}$} & \multirow{2}{*}{$\frac{\text { Subset for alpha }=0.05}{1}$} \\
\hline & & 1 & & \\
\hline Employee & 30 & 91.53 & 9 & 92.33 \\
\hline Teacher & 11 & 92.45 & 7 & 90.57 \\
\hline Worker & 6 & 88.67 & & \\
\hline Business & 2 & 88.00 & & \\
\hline \multicolumn{5}{|l|}{ Person } \\
\hline Farmer & 1 & 92.00 & & \\
\hline Housewife & & & 64 & 91.33 \\
\hline Others & 30 & 91.57 & & \\
\hline Sig & & .64 & & .72 \\
\hline
\end{tabular}

Table 8

Variance Test Based on Mother's Profession

\begin{tabular}{lccccc}
\hline & Sum of Squares & $d f$ & Mean Square & $F$ & Sig. \\
\hline Between Groups & 12.93 & 2 & 6.46 & .252 & .778 \\
Within Groups & 1971.82 & 77 & 25.61 & & \\
Total & 1984.75 & 79 & & & \\
\hline
\end{tabular}

Parents' Approximate Income - The analysis of variance was used for this hypothesis. According to the results in Table 9, the difference between means of research participants' answer, based on their parent's approximate income, was not significant; and it was higher than 0.05. Therefore, it was concluded that data were likely with a true null, and parent's approximate income has no significant effect on learners' language acquisition.

As the means shown in Table 10, students, whose parent's had more than 2 Million Tomans in the month, had higher scores than others. Nevertheless, the difference was not significant.

\section{Table 9}

Variance Test Based on Parents' Approximate Income

\begin{tabular}{lccccc}
\hline & Sum of Squares & $d f$ & Mean Square & $F$ & Sig. \\
\hline Between Groups & 98.63 & 3 & 32.88 & 1.325 & .273 \\
Within Groups & 1886.13 & 76 & 24.82 & & \\
Total & 1984.75 & 79 & & & \\
\hline
\end{tabular}

\section{Table 10}

Means of English Proficiency Variable Based on Parents’ Approximate Income

\begin{tabular}{lcc}
\multicolumn{1}{c}{ Income } & $\mathrm{n}$ & Subset for alpha $=0.05$ \\
\hline 1 Million Toman & 21 & 91.71 \\
1.5 Million Tomans & 21 & 90.00 \\
2 Million Tomans & 24 & 91.13 \\
More than 2 Million Tomans & 14 & 93.36 \\
Sig & & .23 \\
\hline
\end{tabular}

Research Hypothesis 4 - As it was mentioned earlier, the fourth hypothesis of this research regards participants' gender. It addressed the role of gender in learners' proficiency in English. The following null hypothesis was proposed as follow:

$>\quad \mathrm{H}_{0} 4$. Gender of learners does not play any significant role in their proficiency in English as a foreign language. 
Relationship between Georgian-Persian biliterate additive bilingualism and learners' proficiency in EFL

As presented in Table 11, the mean score of males and females are 91.90 and 90.85 in order. To identify the significance of the mean difference, Independent Sample T-test was utilized. As demonstrated by Table 11, the t-observed $(\mathrm{F}=.536)$ was not significant at $p<.05$, indicating that there is not a meaningful difference between males and females in their proficiency in English as a foreign language. So, the fifth null hypothesis is supported.

Table 11

Results of Independent Sample T-test for Gender

\begin{tabular}{|c|c|c|c|c|c|c|c|}
\hline \multicolumn{3}{|c|}{ Independent T-test for Comparing Means } & \multicolumn{2}{|c|}{$\begin{array}{l}\text { Levene's Test for } \\
\text { Equality of Variances }\end{array}$} & \multirow{2}{*}{ Mean } & & \multirow{2}{*}{ Variable } \\
\hline p-Value & $\begin{array}{l}\text { degrees of } \\
\text { freedom }\end{array}$ & $T$ & p-Value & $F$ & & & \\
\hline .352 & 78 & .936 & .466 & .536 & $\begin{array}{l}91.90 \\
90.85\end{array}$ & $\begin{array}{c}\text { Male } \\
\text { Female }\end{array}$ & English Learning \\
\hline
\end{tabular}

\section{Discussions}

In response to the first research question, the first null hypothesis was formulated: There is no significant relationship between Georgian and Persian biliterary additive bilingualism on learners' proficiency in English as a foreign language. The data displayed that the difference between means of English proficiency scores in two separate groups (monolinguals and bilinguals) was not significant, and it was higher than 0.05. So, it was concluded that data were likely with a true null.

About the second research question, this null hypothesis was posed. There is no significant relationship between languages typology and third language acquisition. The learners' scores in final exam showed that the difference between means of monolinguals' and bilinguals' groups was less than 0.05 , and it was not noticeable. Thus, the second null hypothesis would be supported.

About the third research question, this null hypothesis was expressed: Income, education, and profession of both parents have no effect on enhancing learners' language acquisition. The findings of learners' personal information sheet showed these results: students, whose fathers had M.A, had higher scores than other students. Students, whose fathers were a teacher, had the highest scores. Students, whose mothers had Associate of Art, had the highest scores. Scores for learners, whose mothers were employee, were the highest. Students, whose parent's had more than 2 Million Tomans in the month, had higher scores than others. Nevertheless, the difference was not significant in means for all mentioned variables above. So, the third null hypothesis would be supported.

The fourth research question focused on the gender. It sought to find any significant difference between males and females in scores of their final exam. In response to the last research question, this null hypothesis was formulated: Gender of learners does not play any significant role in their proficiency in English as a foreign language. Findings showed that the mean score of males and females are 91.90 and 90.85 in order. Independent Sample T-test was utilized to identify the significance of the mean difference

As demonstrated by Table 11 , the t-observed $(\mathrm{F}=.536)$ was not significant at $p<.05$, indicating that there is not a meaningful difference between males and females in their proficiency in English as a foreign language. So, the fifth null hypothesis is supported.

\section{Conclusions}

Based on the analysis, the findings of the study supported all the four null hypotheses of the study. Thus, according to the results of the present study, although one cannot make big claims regarding the generalizability of the findings, the following results were, eventually drawn. According to the findings of the current study for 
the first research question, there is no significant relationship between Georgian and Persian bilingualism and proficiency in learning English.

According to the findings of the current study for the second research question, third language acquisition does not affect by the languages typology. So, Slavic Languages (like Georgian) do not play a special role in learning English as a foreign language. But, this point would be noticeable that "sometimes the term formal similarity refers to relationship of similarity between the features or components of two or more languages without necessarily implying a genetic relationship between them" (De Angelis, 2007, p. 22).

According to the findings of the current study for the third research question and transcribing the data gathered through learners' personal information sheet, education, and profession of both parents have no effect on enhancing learners' language acquisition. According to the findings of the current study for the fourth research question, it is concluded that gender of learners does not play any significant role in their proficiency in English.

\subsection{Theoretical Implications}

The outcomes about the relationship between Georgian-Persian biliterate additive bilingualism on learners' proficiency in English as a foreign language provide new insights. From the theoretical point of view, the findings of this study may make an extensive contribution to the knowledge about Georgian-Persian bilingualism in the Iranian context. This study shed light on some aspects that how the process of language learning, especially English, may be affected by the Georgian-Persian bilingualism. This study partially satisfies its main goal, and it just raises other questions and hypotheses on the issue in the reader's mind in addition to the addressed research questions.

\subsection{Pedagogical Implications}

Since this study familiarizes the readers with the Georgian-Persian biliterate additive bilingualism, the results can be beneficial for English teachers who were after finding new ways of dealing with the monolinguals, bilinguals, and multilinguals. The findings of the present study help the teachers in comparing the participants with different features of the languages. The English teachers will be aware of the effects of bilingualism, languages typology, parents' features, and learner's gender on proficiency in English learning as a foreign language.

\section{References}

Cenoz, J., \& Valencia, J. (1994). Additive trilingualism: Evidence from the Basque Country. Applied Psycholinguistics, 15(2), 195-207. https://doi.org/10.1017/S0142716400005324

Cenoz, J., Hufeisen, B., \& Jessner, U. (Eds.) (2001). Cross-linguistic influence in third language acquisition: psycholinguistic perspectives. Clevedon: Multilingual Matters.

Cenoz, J. (2013). The influence of bilingualism on third language acquisition: Focus on multilingualism. Language Teaching, 46, 71-86. https://doi.org/10.1017/S0261444811000218

De Angelis, G. (2007). Third or additional language learning. Clevedon: Multilingual Matters.

Dewaele, J. M. (2010). Multilingualism and affordances: Variation in self-perceived communicative competence and communicative anxiety in French L1, L2, L3 and L4. International Review of Applied Linguistics in Language Teaching, 48, 105-129. https://doi.org/10.1515/iral.2010.006

Herdina, P., \& Jessner, U. (2002). A dynamic model of multilingualism: Perspectives of change in psycholinguistics. Clevendon: Multilingual Matters.

Jaspaert, K., \& Lemmens, G. (1990). Linguistic evaluation of Dutch as a third language. In M. Byram \& J. Leman (Eds.), Bicultural and trilingual education: The Foyer model in Brussels (pp. 30-56). Clevedon: Multilingual Matters.

Martínez, J. F., Alison L. B., Deirdre, K., Becky, H., H., \& Stacey, B. (2010). Measuring opportunity to learn and 
Relationship between Georgian-Persian biliterate additive bilingualism and learners' proficiency in EFL academic language exposure for English language learners in elementary science classrooms. Retrieved from http://files.eric.ed.gov/fulltext/ED512652.pdf

Raven, J., Raven, J. C., \& Court, J. H. (2003). Manual for Raven's progressive matrices and vocabulary scales. San Antonio, TX: Harcourt Assessment.

Rundell, M., \& Fox, G. (Eds.) (2002). MacMillan English dictionary for advanced learners. London: Macmillan Education.

Sanders, M., \& Meijers, G. (1995). English as L3 in the elementary school. ITL Review of Applied Linguistics, 107(8), 59-78.

Sanz, C. (2000). Bilingual education enhances third language acquisition: Evidence from Catalonia. Applied Psycholinguistics, 21, 23-44. https://doi.org/10.1017/S0142716400001028

Swain, M., Lapkin, S., Rowen, N., \& Hart, D. (1990). The role of mother tongue literacy in third language learning. Language, Culture, and Curriculum, 3(1), 65-81. https://doi.org/10.1080/07908319009525073

Wagner, D. A., Spratt, J. E., \& Ezzaki, A. (1989). Does learning to read in a second language always put the child at a disadvantage? Some counterevidence from Morocco. Applied Psycholinguistics, 10, 31-48. https://doi.org/10.1017/S0142716400008407 
Googoonani, M., \& Simin, S. 